\title{
Como acessar a caixa-preta do WhatsApp? Mapeamento dos métodos de publicações científicas que tratam sobre política em uma plataforma fechada de mídia digital
}

\author{
Geraldo Bulhões Bittencourt Filho1 \\ Jorge Martins Rosa²
}

\begin{abstract}
Resumo:
Neste artigo, buscou-se responder à pergunta: "Quais são os métodos utilizados em artigos científicos sobre política que analisam empiricamente grupos e mensagens no WhatsApp?” Para isso, procurou-se efetuar uma revisão sistemática de literatura dentro das bases Scopus, Web of Science e Google Scholar, algumas das mais revisadas por pares da atualidade. Nelas, foram realizadas pesquisas que combinam a palavra "WhatsApp" com cada um dos seguintes termos: political, government, election e protest. Dos 51 resultados, identificaram-se os métodos e a forma que foi realizada a coleta de dados no WhatsApp. Conclui-se que há um equilíbrio entre abordagens e que não existe uma metodologia predominante para a coleta de dados.
\end{abstract}

Palavras-chaves: WhatsApp, política, métodos

\begin{abstract}
:
In this article, we sought to answer the question: "What are the methods used in scientific articles on politics that empirically analyze groups and messages on WhatsApp?" To this end, we sought to carry out a systematic literature review within the Scopus, Web of Science and Google Scholar databases, some of the most peer-reviewed today. In them, searches were carried out that combine the word WhatsApp with each of the following terms: political, government, election and protest. Of the 51 results, the methods and the way in which data collection was performed on WhatsApp were identified. It is concluded that there is a balance between approaches and that there is no predominant methodology for data collection.
\end{abstract}

Keywords: WhatsApp, politics, methods

\footnotetext{
' Doutorando em Ciências da Comunicação pela Universidade NOVA de Lisboa. Jornalista permanente do Instituto Federal de Sergipe. geraldo.bittencourt@ campus.fcsh.unl.pt 2 Doutor em Ciências da Comunicação pela Universidade NOVA de Lisboa. Professor na Universidade NOVA de Lisboa. dedalus.jmmr@gmail.com
} 


\section{VOZES $_{\& \text { DIÁLORO }}^{\mid}$}

Itajaí, V. 20, n.01, jan-jun 2021

\section{Introdução}

Este trabalho propõe o entendimento de como os pesquisadores estão criando soluções metodológicas para ingressar no universo das novas redes sociotécnicas - a mídia digital escolhida foi o WhatsApp, uma vez que apresenta um desafio para pesquisas empíricas por não possuir uma interface aberta para a coleta dos dados, fazendo parte das plataformas que compõem a "era pós-API (Application Programming Interfaces)". Privilegiaram-se trabalhos que tratem sobre política, visto que se observa que é um dos assuntos capazes de obter reverberação viral através da plataforma. Uma pesquisa encomendada pela agência de fact-checking Aos Fatos sobre os hábitos dos brasileiros na internet mostrou que mídias sociais ou aplicativos de mensagem instantânea, como o WhatsApp, são os principais canais de acesso às notícias da população, com 33,8\% das respostas. O grupo controlador do WhatsApp informou que possui uma base de 120 milhões de usuários no Brasil, atingindo $56 \%$ da população e $98 \%$ das pessoas que possuem um smartphone e o acessam todos os dias. De acordo com essas informações, percebe-se como é relevante mapear metodologicamente os estudos sobre política que possuem um aplicativo da abrangência do WhatsApp como objeto.

Como percurso teórico para embasar o artigo, entende-se como importante apresentar um panorama sobre a comunicação de massa, no contexto das ideias de Jürgen Habermas, bem como discutir autores que trabalharam o conceito de esfera pública do filósofo alemão com o surgimento da internet, a exemplo de Zizi Papacharissi, Manuel Castells e Yochai Benkler. Alguns estudos que podem dar pistas sobre a lógica de distribuição das mensagens no WhatsApp foram apresentados, nomeadamente as teorias da Imitação, de Gabriel Tarde; da Memética, de Richard Dawkins; bem como a Teoria Ator-Rede (ANT), de Bruno Latour. Para entender os caminhos metodológicos, realizouse um exaustivo trabalho de busca nas bases Scopus, Web of Science e Google Scholar, nas quais foram realizadas pesquisas que combinam a palavra "WhatsApp" com cada um dos seguintes termos: political, government, election e protest. Após o trabalho de busca nos indexadores com a aplicação de critérios específicos, alcançaram-se 51 artigos únicos, os quais foram examinados no que toca aos métodos de pesquisa e de coleta de dados. Foram fornecidas, ainda, análises complementares ligadas à origem dos estudos e ao aumento do interesse científico no tempo.

\section{Referencial Teórico}

Na obra Transformações Estruturais da Esfera Pública, o filósofo alemão Jürgen Habermas empreendeu uma análise histórica que mostrou a estruturação e as reestruturações da esfera pública, definida pelo autor como uma arena na qual pessoas privadas reunidas em um público discutem questões de pertinência para a sociedade com 


\section{VOZES $_{\text {\&IÁLORO }}^{\mid}$}

Itajaí, V. 20, n.01, jan-jun 2021

os detentores do poder público e da autoridade e possuem a capacidade de influenciá-los (2003, p. 42). Depois de tratar de aspectos culturais, sociais, políticos e ideológicos da esfera pública, Habermas apresenta a ideia de que os partidos políticos e as associações, por terem capacidade de abrangência (incluir os trabalhadores, por exemplo), é que reuniriam as condições para viabilizá-la (2003, p. 200). O surgimento dos meios de comunicação de massa, por sua vez, permitiu o impulsionamento das vozes que compunham a esfera pública. As teorias da comunicação, entretanto, atravessaram um momento de modificações estruturais a partir da década de 70 do século XX e imprimiram um ritmo considerável de novas teorias entre os anos 80 e 90 no mesmo século. O que alterou substancialmente a produtividade de acadêmicos de todo o mundo foi a inserção de um novo artefato no rol de preocupações sobre os meios de comunicação: a internet, cuja principal característica é a interatividade.

Nas primeiras teorias formuladas após a chegada da internet, percebe-se muitas vezes a esperança da viabilização da democracia da mídia e a concretização da esfera pública. Para Benkler, a internet possibilitou que os cidadãos estabelecessem uma nova relação com a esfera pública. "Eles não precisam mais ser consumidores e passivos espectadores. Eles podem se tornar criadores e assuntos principais. É nesse sentido que a internet democratiza” (2006, p. 272). Manuel Castells enfatiza a novidade da nova esfera: "A construção da nova esfera pública na sociedade da rede prossegue construindo protocolos de comunicação entre diferentes processos de comunicação" (2009, p. 125). Por outro lado, estudiosos menos otimistas ponderaram a força democratizante das plataformas de mídias digitais ao mostrar que, na internet, há uma concentração igual ou maior de vozes do que nas mídias tradicionais (ROGERS, 2013, p. 39). Percebeu-se, também, a equiparação de falta de abertura ao observar que os dez principais sites de notícias recebem $1 / 4$ de todas as visitas da web, enquanto os dez principais jornais impressos americanos representam 19\% da circulação total (HINDMAN, 2009, p. 110).

As diversas teorias apresentadas até aqui possibilitam a observação de que os fluxos comunicacionais já foram bastante estudados pelos teóricos da comunicação de massa, especialmente no século XX. Após o surgimento das mídias digitais com o recurso da interatividade, nota-se que os estudos têm se voltado ao entendimento da forma como a mensagem "viaja" entre as redes computacionais e atinge um ou vários receptores. A internet e os meios de comunicação que foram criados em sua base tornaram-se um campo fértil para pesquisas sobre a topologia da rede em virtude desses meios terem como características serem descentralizados e não-hierárquicos.

Uma das correntes teóricas que buscou compreender a forma que a mensagem se expande entre as pessoas e o caminho que ela percorre utilizou entendimentos firmados no estudo dos genes e da memética. Richard Dawkins explica que a tríade evolutiva genética (replicação, variação e seleção) se aplica tanto no gene quanto no meme. A diferença reside na transmissão: enquanto os genes replicam por herança, os memes 


\section{VOZES $_{\text {\&IÁLORO }}^{\mid}$}

Itajaí, V. 20, n.01, jan-jun 2021

replicam por imitação. Sempre que alguém assume algo de outra pessoa por imitação, um meme é replicado. Como há mais memes do que canais, ao ser executado o algoritmo evolutivo, a mente que recebe as informações retém apenas o meme com o melhor código (2018, p. 206). Sampsom (2012, p. 56) explica que os pressupostos de que a replicação do meme se dá por imitação foram influenciados pelas ideias do filósofo Gabriel Tarde, que desenvolveu a noção de contágio social, segundo a qual a comunicação é derivada de uma repetitiva e, principalmente, acidental sucessão de desejos que se espalha de forma inconsciente através dos encontros sociais imitativos. Esse processo ocorre em pontos infinitos, que vão formando fluxos opinativos. Alguns são linhas frágeis, que desfalecem; outros fluxos se ampliam em inúmeras intensidades de formação virais.

A lógica tardiana, por sua vez, influenciou a criação da Teoria Ator-Rede (ANT), de Bruno Latour. A partir das inquietações sobre a crença da sociedade moderna na razão científica e a rejeição das condições históricas, antropológicas e materiais, Latour afirmou que o desenvolvimento social não era estático, mas dinâmico, e que o ato científico ultrapassa os limites do contexto social em que a questão estava inserida, alcançando, inclusive, atores não-humanos no processo. Na ANT, o ator pode ser um animal, smartphones, computadores, sensores, instituições ou pessoas e é definido pelo papel que possui e pela sua efetividade na rede, que representa interligações com outros atores - ou nós, como são também chamados. As redes são multidirecionais e tocam outras com alguma similaridade, interferindo-se e influenciando-se. Uma proposição será aceita levando em consideração a capacidade de inscrição (representação por imagens ou gráficos), a legibilidade (tornar compreensível) e a imutabilidade (capacidade de obteremse os mesmos resultados quando repetidas as circunstâncias dos fenômenos) (LUNA FREIRE, 2006, p. 46-65).

Após o surgimento das mídias digitais e dos seus recursos que abriram maiores possibilidades interativas, o processo de mapeamento das etapas que ocorrem entre a criação de uma mensagem e a chegada no receptor tornou-se mais complexo. O modelo de esfera pública proposto por Habermas, segundo o qual pessoas privadas se reúnem num público para debater questões de pertinência da sociedade e influenciar a tomada de decisão acerca dos temas sensíveis da vida social, precisa abraçar a miríade de perspectivas que se abrem com as novas formas de espalhamento da informação. Como Tarde e Latour colocaram em perspectiva em suas respectivas teorias, a sociedade é formada pela união dos aspectos sociais, técnicos e naturais, e a informação percorre um caminho imprevisível, no qual a formação dos nós depende da adesão ou não do ator social que está a seguir. Neste sentido, Zizi Papacharissi (2009, p. 244), ao desenvolver o conceito de esfera virtual, chegou à conclusão de que as mídias digitais apresentam o potencial, ainda não efetivado, de criar o ambiente democrático da busca pelo consenso previsto por Habermas. 


\section{VOZES $_{\text {\&IÁLORO }}^{\mid}$}

Itajaí, V. 20, n.01, jan-jun 2021

\section{Metodologia}

A pergunta que norteia o artigo é: Quais são os métodos utilizados em artigos científicos sobre política que analisam empiricamente grupos e mensagens no WhatsApp? Para respondê-la, elaborou-se uma revisão sistemática da literatura, que, segundo Sampaio e Mancini, é um trabalho útil para descobrir os assuntos mais debatidos no mundo acelerado e mutável da pesquisa científica, sendo especialmente importante para indicar caminhos para pesquisas futuras e mapear os métodos mais utilizados em uma área específica (2007, p. 23). No desenvolvimento do artigo, foram efetuadas buscas nas bases de dados científicas Scopus, Web of Science e Google Scholar, algumas das mais revisadas por pares da atualidade. No motor de busca de cada uma das plataformas, foi realizada a pesquisa que combina a palavra "WhatsApp" com cada um dos seguintes termos: political, government, election, protest. Os filtros foram escolhidos de modo que os resultados ofertados fossem apenas: 1) artigos científicos ou papers de conferência; 2) trabalhos das áreas de "ciências humanas" ou "ciências sociais"; 3) pesquisas que contenham alguma das palavras buscadas no título ou nas palavras-chave; 4) pesquisas escritas em português, inglês ou espanhol; e 5) trabalhos publicados entre 2009 (ano de lançamento do aplicativo) e 2021. Foram excluídas revisões sistemáticas, repetições (trabalhos que sejam apresentados em mais de uma base de dados), arquivos com links quebrados e publicações incompletas. Dos resultados, fez-se a identificação dos métodos utilizados e a forma como foi realizada a coleta de dados no WhatsApp. Após a obtenção dos resultados, os métodos de pesquisa foram catalogados e apresentados, em forma de gráfico, por plataforma e, depois, de forma geral, de modo a mostrar se há uma solução metodológica prevalente aplicada pelos autores até aqui. Em seguida, também estatisticamente, foram revelados os métodos para coleta de dados.

\section{Análises}

Ao lançar diretamente no motor de buscas das bases de dados o código booleano que corresponde aos objetivos buscados por este artigo, obtiveram-se 3.072 resultados 135 na Scopus, 97 na Web of Science e 2.840 na Google Scholar. A discrepância entre os resultados justifica-se pelo fato de que o sistema acadêmico do Google realiza busca em outras vinte plataformas, tornando expressivo o alcance. A etapa seguinte corresponde à aplicação dos critérios de exclusão estipulados para esta pesquisa e que está descrito na seção anterior deste trabalho - neste ponto, reduziu-se o número de pesquisas para 113 publicações. Para eliminação dos trabalhos repetidos, cruzaram-se os resultados de cada repositório, através do título, utilizando o software Microsoft Excel - chegou-se, então, aos 51 artigos distintos para a realização da revisão sistemática de literatura. 


\section{VOZES $_{\& \text { DIÁLORO }}^{\downarrow}$}

Itajaí, V. 20, n.01, jan-jun 2021

Nas três plataformas de pesquisa, 2019 foi o ano que mais obteve publicações que buscavam relacionar as temáticas ligadas à política com a utilização do WhatsApp como ferramenta de comunicação. Na Scopus, foram 8 trabalhos; na Web Of Science, 3; e no Google Scholar, 9, totalizando 20 trabalhos, ou seja, 39,2\% das publicações totais. Embora 2019 seja o ano com mais pesquisas, 2017 pode ser visto como o ano em que o WhatsApp e os seus usos na esfera política começaram a chamar a atenção dos pesquisadores de maneira mais consistente - levando-se em consideração os resultados nas três plataformas, 2017 recebe mais pesquisas do que a soma dos oito anos anteriores: são 12 publicações científicas em 2017 e apenas 5 entre 2009 e 2016. O gráfico 1 mostra a curva de crescimento das pesquisas utilizando o aplicativo dentro do corpus deste trabalho.

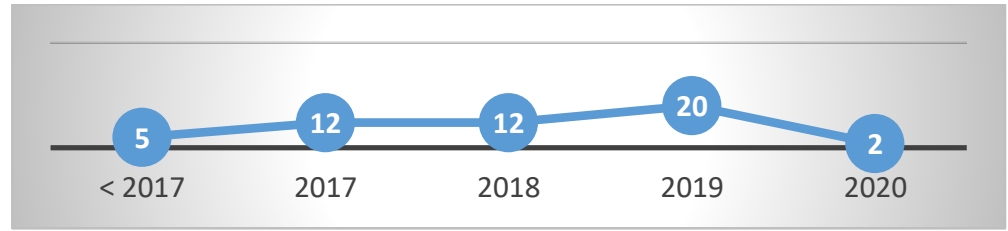

Gráfico 1: Aumento do interesse científico sobre política no WhatsApp

Publicação de Pang e Woo (2019, p. 5) sobre a utilização do WhatsApp no contexto do engajamento cívico da sociedade encontra números semelhantes ao desta pesquisa na escala de crescimento por ano. As autoras levantam a hipótese de que o aplicativo obteve adesão massiva somente após a implantação do sistema de criptografia ponta-a-ponta, em 2016, recurso que tornou mais privativos os diálogos dentro da plataforma e gerou mais confiança na utilização do software móvel não apenas por usuários particulares, mas por organizações. Nos 51 trabalhos analisados, observou-se que o número de países que foram objeto de estudo de caso estava em consonância com aqueles que mais utilizam o aplicativo, situação que evidencia que o interesse acadêmico sobre o WhatsApp acompanha a utilização do sotfware pelo mundo. Com mais de 2 bilhões de usuários em 180 países (WHATSAPP, 2021), a lista das nações cuja população, em números proporcionais, mais aderiu ao mensageiro instantâneo é: 1) Índia; 2) Brasil; 3) Indonésia; 4) México; e 5) Itália (CLARK e WEIR, 2019). Entre os artigos estudados nesta pesquisa, os países que tiveram suas realidades mais analisadas cientificamente em relação ao uso do WhatsApp foram: 1) Brasil - 12 artigos; 2) Índia - 6; 3) Nigéria e Malásia - 5 cada; e 5) Indonésia - 4.

Verifica-se que, na lista de estudos que compuseram o corpus deste trabalho, a Malásia e a Nigéria aparecem em dissonância em relação às nações que mais utilizam o aplicativo pelo mundo. Entende-se que a presença da Malásia nos estudos científicos está relacionada às vantagens do uso de um software que garante a segurança das conversas através da criptografia em um país marcado ainda pela censura. De acordo com Johns, o 


\section{VOZES $_{\text {\&IÁLORO }}^{\mid}$}

Itajaí, V. 20, n.01, jan-jun 2021

WhatsApp é um espaço que pode ser definido como "cripto-público", uma vez que permite a proteção criptográfica de conversas e, assim, torna os conteúdos não-rastreáveis por governos de propensão regulatória, como o da Malásia (2020, p. 3). Tapsell vê o aplicativo como a "arma dos fracos" ao ressaltar o seu papel de destaque na queda do grupo político que governava a Malásia há 60 anos, "especialmente na divulgação dos casos de corrupção e de nepotismo do primeiro-ministro Najib Razak e sua esposa, Rosmah Mansor” (2018, p. 10). Já o aparecimento da Nigéria na lista justifica-se pelo massivo uso de um aplicativo "clone" do WhatsApp pela população africana, o GBWhatsApp, que é capaz de fornecer mais recursos que o original, como a possibilidade de usar mais de uma conta no mesmo aparelho e modificar visualmente a tela. Uma pesquisa da Caribou Data (2019), organização especializada no estudo dos hábitos na internet de países emergentes, mostrou que o GBWhatsApp é o segundo mais baixado pela população, atrás apenas do próprio WhatsApp. Os dois softwares juntos justificariam o grande interesse de pesquisadores pelas realidades de países africanos.

À medida em que se observa que o WhatsApp garante a confidencialidade das comunicações nas conversas, percebe-se também que a questão ética é um dos temas que mais surge no escopo dos trabalhos acadêmicos para justificar a adoção do aplicativo como objeto de estudo. As pesquisas que buscam penetrar no WhatsApp enfrentam dois desafios interligados: o de encontrar um método para “acessar a caixa-preta”, bem como utilizá-lo sem violar requisitos éticos ligados à privacidade das conversas. Trinta e nove artigos deste trabalho $(76,4 \%)$ encontraram como solução a realização de pesquisas somente em grupos públicos, as quais não violariam a Política de Privacidade do WhatsApp. Todas as pesquisas que entraram em grupos públicos no WhatsApp declararam que os metadados dos usuários seriam anonimizados, mantendo-se apenas as interações por áudio, vídeo, imagem, emojis e texto. Nesta amostra, observou-se que os autores também declararam que, ao ingressar nos espaços públicos virtuais, publicaram um texto padrão avisando que a presença no grupo e as informações colhidas seriam dirigidas a uma pesquisa de caráter científico, facultando aos administradores dos grupos a exclusão do pesquisador caso discordassem dos objetivos expostos - exceção feita a Chagas et al., que expressamente declararam optar por uma pesquisa encoberta, em que os pesquisadores não revelam sua participação nas arenas de discussão (2019, p. 10). Os demais artigos, 23,6\%, tiveram acesso aos grupos do WhatsApp através de permissões solicitadas previamente ou moveram seus interesses para pesquisas bibliográficas ou documentais

\section{Métodos de pesquisa}

Dentro do corpus deste trabalho, percebeu-se o equilíbrio entre os tipos de pesquisa escolhidos pelos autores para desenvolverem seus estudos - 28 foram classificadas como qualitativas, 20 como quantitativas e 3 empregaram o método misto. Apesar de um 


\section{VOZES \\ DIÁLORO}

Itajaí, V. 20, n.01, jan-jun 2021

dos critérios de filtragem empregados estabelecer como recorte apenas pesquisas nas áreas de ciências humanas e sociais, verificou-se a busca de parceria entre pesquisadores dessas áreas com os estudiosos das ciências exatas. A simbiose justifica-se pelo fato de que os pesquisadores, especialmente os da computação, têm colaborado no desenvolvimento de ferramentas para extração e organização dos dados do WhatsApp. Dentro do conjunto de pesquisas quantitativas identificadas, 13 delas declaram utilizar Análise Descritiva ou Técnicas de Regressão, ambos modelos Estatísticos, como o/um método de análise. Outros 7 trabalhos utilizaram a Análise Quantitativa de Conteúdo para observar a frequência de termos, construções e referências nas conversas. Esses dois métodos respondem por 20 das 51 metodologias empregadas neste recorte. Observou-se ainda que quatro trabalhos optaram pela Análise de Conteúdo com finalidade qualitativa. Embora o aplicativo de mensagens instantâneas seja um recurso digital, seis artigos recorreram à Análise Documental como método de pesquisa, e cinco se dedicaram a discutir as interpelações teóricas entre política e WhatsApp utilizando-se de livros, artigos e apresentações em conferências. A Netnografia, método oriundo da Antropologia, foi utilizada em cinco artigos que buscaram explicar a dinâmica interna dos grupos do WhatsApp.

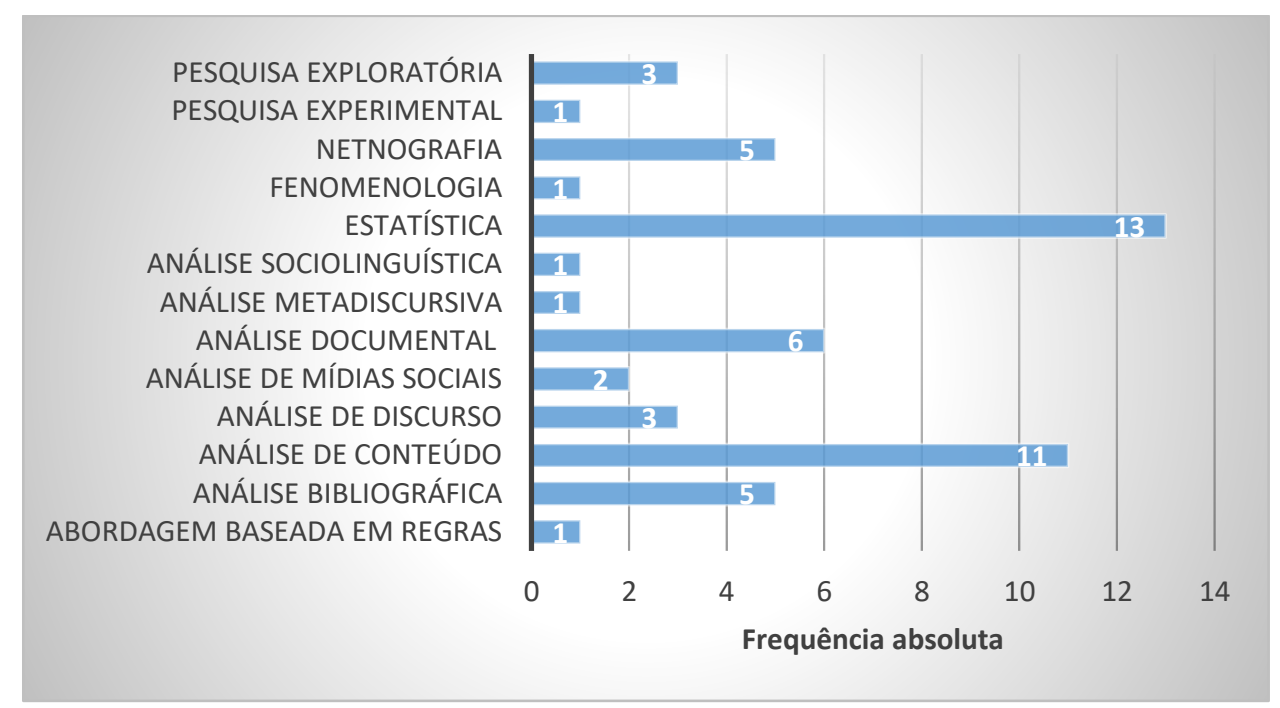

Gráfico 2: Métodos de pesquisa aplicados nos artigos filtrados

De acordo com os dados coletados, ainda não é possível observar uma prevalência de métodos empregados nos artigos, o que revela que os pesquisadores ainda estão realizando testes para encontrar o método que melhor se adeque ao objeto. Acredita-se que essa variedade se justifica em virtude do interesse de pesquisadores pelo contexto político no WhatsApp ter aumentado somente em 2017. Na perspectiva de entender melhor o fenômeno, três artigos optaram por realizar Pesquisas Exploratórias, as quais tratam de assuntos com pouco ou nenhum estudo anterior a seu respeito e leva o pesquisador, frequentemente, “à descoberta de enfoques, percepções e terminologias 


\section{VOZES}

Itajaí, V. 20, n.01, jan-jun 2021

novas para ele, contribuindo para que, paulatinamente, seu próprio modo de pensar seja modificado" (PIOVESAN, 1995, p. 321). Piaia e Alves também afirmaram que ainda não é possível observar unidade metodológica ou preferência por um método específico em estudos no WhatsApp (2019, p. 10).

\section{Métodos de coleta de dados}

Observa-se que uma das questões dificultadoras mais citadas pelos pesquisadores diz respeito à coleta de dados. Sem um local digital comum e aberto, observou-se que as estratégias utilizadas por eles para ingresso nos grupos variaram entre a técnica conhecida como bola de neve e a pesquisa manual ou automatizada de grupos públicos através de buscadores. Doze pesquisas não ingressaram em grupos e optaram por investigações bibliográficas ou documentais (questionários, entrevistas e matérias jornalísticas). Uma vez dentro dos grupos, 10 artigos optaram por realizar a coleta de dados através da observação (participante ou não). Outros 10 trabalhos declararam realizar a extração de dados de forma manual, e oito de maneira automática.

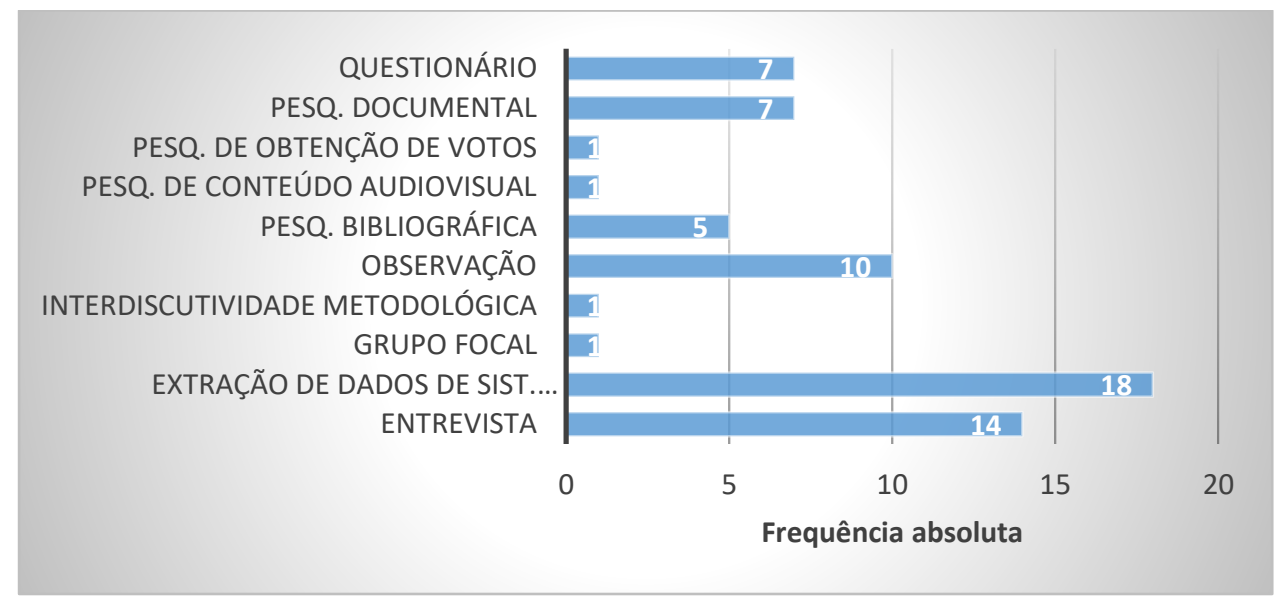

Gráfico 3: Métodos de coleta de dados mais utilizados

As aplicações que permitiram a extração automática de dados foram: WhatsApp Monitor (aparece em duas pesquisas), Selenium (aparece em duas), Aggie, El Diablo e dois aplicativos sem nome - um desenhado em código SQLite e outro que faz uso da combinação de ChatVisualizer com um código desenvolvido em linguagem C. Com pequenas variações no que diz respeito ao objetivo final do aplicativo, todos os sistemas citados automatizam a busca de grupos públicos em sítios variados e efetuam de forma automática o registro de todos os arquivos e conversas dos grupos, anonimizando as marcas de identificação. Observou-se que 5 das 8 pesquisas que usavam as aplicações automáticas tinham como um dos interesses entender a relação do WhatsApp com a disseminação viral de informações falsas. Segundo Benevenuto (2020), os cientistas da computação buscam 


\section{VOZES $_{\text {\&IÁLORO }}^{\mid}$}

Itajaí, V. 20, n.01, jan-jun 2021

encontrar padrões em comum nas notícias falsas para tentar automatizar a detecção dessas informações.

\section{Discussão}

A utilização do aplicativo de mensagens instantâneas WhatsApp enfrenta questionamento antagônicos, especialmente no campo científico, o que implica sobremaneira com a solução metodológica que os pesquisadores podem alcançar para realizar estudos com foco no sistema. Os críticos da utilização dos aplicativos de mensagens instantâneas como objeto de pesquisas acadêmicas mencionam como entrave a separação entre o público e o privado. Dentro do contexto da existência de intimidade, e não do privado como privação, Hanna Arendt aponta que o privado trata da diferença consciente do que deve ser exibido e do que deve ser ocultado (1997, p. 82). A passagem específica de Arendt pode ser transportada ao propósito da individualidade das relações estabelecidas dentro das conversas entre pessoas privadas no WhatsApp, que foi reforçado em 2016 com a implantação do sistema de criptografia de ponta a ponta. O perigo da ultrapassagem indevida deste limiar foi observado por Saudiah e Salamah (2017, p. 1099), Caetano et al. (2018, p. 4) e Narayanan et al. (2019, p. 6). No espectro oposto, Arendt apresenta também o seu entendimento sobre a esfera pública, que corresponde a um espaço comum baseado no uso da palavra e do poder de convencimento, nos moldes Aristotélicos (1997, p. 34). Habermas estende esse entendimento para o uso do melhor argumento em busca do consenso (2003, p. 236). Os dois apontamentos também podem ser visualizados no contexto das plataformas de mensagens, as quais são capazes de reunir pessoas com interesses diversos em um espaço fechado para discutir assuntos de interesse geral em que podem ser privilegiados os argumentos mais persuasivos e consistentes.

Embora se verifique a preocupação com as questões relativas à privacidade e à necessidade de uma solução metodológica que se adéque a essa problemática para que seja possível entrar cientificamente no universo do WhatsApp, percebe-se também o amplo reconhecimento do uso aplicativo como um fator determinante para que os usuários tenham voz garantida em cenários de restrição de direitos civis. A inserção da criptografia no WhatsApp, inclusive, é apontada como um dos elementos responsáveis por permitir a livre circulação de informações em países como a Índia. Breindl (2010, p. 12) reconheceu o potencial da internet para o envolvimento cívico, embora isso muitas vezes leve a sanções e vigilância dos estados. Na Índia, como não era possível romper a proteção das conversas por criptografia, o governo solicitou ao WhatsApp o compartilhamento dos metadados dos usuários, situação que colocou a privacidade muitos cidadãos em risco (ARUN, 2019, p. $6)$.

O controle da informação por Estados totalitários dentro do contexto do WhatsApp também enfrenta outra grande dificuldade: a viralidade da mensagem, que se 


\section{VOZES $_{\text {\&IÁLORO }}^{\mid}$}

Itajaí, V. 20, n.01, jan-jun 2021

propaga de maneira veloz. Entretanto, esse modelo epidemiológico traz como efeito colateral a disseminação de informações falsas. Neste aspecto, Cesarino cita a capilaridade sem precedentes permitida pelas plataformas de mídias digitais, como o WhatsApp, e a relação não-mediada do sistema, que não se baseia mais na interlocução de jornalistas ou apresentadores, mas na confiança atribuída ao seu interlocutor como fundamentais para disseminar as informações (2018, p. 15-16). Em outras palavras, o diferencial do aplicativo para disseminação de informações falsas é a possibilidade de interação "um-um” e a relação de proximidade, familiar ou profissional, com a fonte emissora. A afirmação de Cesarino está em consonância com os preceitos da Teoria da Imitação do autor francês Gabriel Tarde, que prevê a propagação da informação viral através do contágio social descentralizado (SAMPSOM, 2012, p. 56-57). Abdin (2019, p. 10), Canavilhas et al. (2019, p. 7-8), Machado et al. (2019, p. 1.017) e Evangelista e Bruno (2019, p. 17) também trataram da questão do compartilhamento de informações falsas tendo como pano de fundo a eleição presidencial do Brasil de 2018. Um apontamento comum entre os três autores era o de que havia uma mesclagem entre coordenação de ações de disseminação viral de informações no WhatsApp com manifestações de apoio genuínas. Para conseguir dar cabo da velocidade na transmissão da informação e entender a organização do fluxo informativo, os pesquisadores concordaram que é necessário lançar mão de estratégias que mesclem técnicas metodológicas manuais e automáticas tanto para ingresso nos grupos públicos quanto para coleta dos dados.

\section{Conclusão}

A elaboração de uma revisão sistemática de literatura com foco em um aplicativo de mensagens instantâneas, como o WhatsApp, possui relevância principalmente em virtude da influência dessa tecnologia nos campos científico e político. As plataformas de mídias sociais instantâneas - que não é apenas o WhatsApp, mas também são o Telegram e o WeChat - mudaram o paradigma da transmissão da informação e moveram o olhar especialmente para a relação entre os indivíduos e o caminho da mensagem. Para futuras pesquisas, verifica-se a necessidade de alargar o objeto e incluir nas buscas também o Telegram e o WeChat, uma vez que cada um possui especificidades que merecem ser levadas em consideração - como a capacidade do Telegram de abarcar em um único grupo 100 mil pessoas (os chamados supergrupos) e como isso impacta na disseminação de um conteúdo; bem como a inexistência de criptografia de ponta a ponta no WeChat, aplicativo usado basicamente na China e em Hong Kong - e como essa característica pode alterar a confiança dos usuários na plataforma, especialmente para o tratamento de informações políticas. 


\section{VOZES $_{\& \text { DIÁLORO }}^{\mid}$}

Itajaí, V. 20, n.01, jan-jun 2021

Nos 51 artigos que compuseram o corpus deste trabalho, observou-se um equilíbrio entre as abordagens qualitativas e quantitativas, mesmo com a filtragem imposta na pesquisa estabelecendo somente as ciências humanas e sociais como áreas. Verificou-se que o equilíbrio tem relação direta com o interesse dos profissionais das ciências da computação em desenvolver aplicativos para coleta de dados no WhatsApp, que é um sistema computacional, e do interesse dos pesquisadores das ciências humanas em métodos como a Estatística e a Análise de Conteúdo - o primeiro totalmente quantitativo e o segundo com ampla possibilidade quantitativa. Verificou-se que o trabalho conjunto entre pesquisadores das ciências sociais e da computação teve como principal propósito o desenvolvimento de instrumentos capazes de realizar a coleta e a organização automatizada de dados. Entre os métodos usados tradicionalmente pelos pesquisadores das ciências sociais, observou-se a ocorrência mais prevalente da Netnografia e das análises Bibliográfica e Documental.

Neste levantamento, verificou-se que o interesse crescente do WhatsApp como objeto de estudo de pesquisadores em todo o mundo acompanhou a utilização do aplicativo pela população. Destaque se faz ao Brasil, à Indonésia e à Índia, que ocupam a parte de cima da lista tanto de pesquisas acadêmicas quanto de prevalência de uso proporcional pelas pessoas. Além dos três países, verifica-se que os contextos da Malásia e da Nigéria também são bastante estudados e está em consonância com o uso da aplicação no cotidiano. Nos países asiáticos e africanos, constatou-se que a utilização do WhatsApp dentro do contexto político está relacionada à possibilidade de driblar a censura estatal. Diante da importância do aplicativo no contexto desses países, percebe-se como importante, para estudos futuros, a realização de revisões sistemáticas de literatura com recortes mais fechados por continente, de modo a ampliar a compreensão do estado da arte das pesquisas especificamente nas regiões estudadas e permitir a comparação do uso político da ferramenta de troca de mensagens em diferentes regiões do globo.

\section{Referências Bibliográficas}

ABDIN, Latifa. Bots and Fake News: The Role of WhatsApp in the 2018 Brazilian Presidential Election. Intersections Cross-sections 2019 Graduate Conference, 2019.

ARENDT, Hanna. A condição Humana. Rio de Janeiro, Forense Universitária, 2007.

BENEVENUTO, Fabrício. Defesa de Tese Tatiana Dourado: Fake News na Eleição Presidencial de 2018 no Brasil. Disponível em: https://www.youtube.com/watch?v=KEhLCWcDdZA Acesso em 29 de abril de 2021.

BENKLER, Yochai. The wealth of networks. New Haven, CT: Yale University Press, 2006.

BLACKMORE, Susan. The Meme Machine. Oxford, Oxford University Press, 1999. 


\section{VOZES $_{\text {\&IÁLORO }}^{\mid}$}

Itajaí, V. 20, n.01, jan-jun 2027

BURGESS, Jean; GREEN, Joshua. YouTube e a Revolução Digital. Cambridge: Polity Press, 2009

CANAVILHAS, João; COLUSSI, Juliana; MOURA, Zita-Bacelar. Desinformación en las elecciones presidenciales 2018 en Brasil: un análisis de los grupos familiares en WhatsApp”. El profesional de la información, v. 28, n.5, 2019.

CARIBOU DATA. Compreender como as pessoas usam aplicativos, consomem dados e compram recargas em diferentes redes e modalidades. Disponível em https://www.v2.cariboudata.com/copy-of-app-developers-1 Acesso em 29 de janeiro de 2021

CASTELLS, Manuel. O Poder da Comunicação. Oxford, Oxford University Press. 2009 .

CESARINO, L. Populismo digital: roteiro inicial para um conceito, a partir de um estudo de caso da campanha eleitoral de 2018. Disponível em: https://bit.ly/3cXYg4z Acesso em 20 de maio de 2020

DAWKINS, Richard. O Gene Egoísta. Colecção Ciência Aberta, 2018.

CLARK, Douglas; WEIR, Corinne. WhatsApp: A Key Driver of Mobile Messaging Growth.

Disponível $\mathrm{em}$ https://www.emarketer.com/newsroom/index.php/whatsapp-a-key-driver-of-mobilemessaging-growth/ Acesso em 12 de janeiro de 2021

EVANGELISTA, R; BRUNO, F. WhatsApp e instabilidade política no Brasil: alvo mensagens e radicalização política. Revisão de Políticas da Internet, 8, 2019. DOI: 10.14763 / 2019.4.1434

GARIMELLA, K.; TYSON, G. WhatApp Doc? A First Look at WhatsApp Public Group Data. Twelfth International AAAI Conference on Web and Social Media, 2018.

GOMES, Wilson. A democracia no mundo digital: história, problemas e temas. São Paulo, Edições SESC, 2018

HABERMAS, Jürgen. Mudança estrutural da esfera pública: investigações quanto a uma categoria da sociedade burguesa. Tradução: Flávio R. Kothe. Rio de Janeiro: Tempo Brasileiro, 2003

HINDMAN, Matthew. The Myth of Digital Democracy. Princeton University Press, 2009.

JOHNS, Amelia. 'This will be the WhatsApp election': Crypto-publics and digital citizenship in Malaysia's GE14 election. Disponível em https://bit.ly/3d4Ymrj Acesso em 20 de maio de 2020.

LATOUR, Bruno. On Actor-Network Theory. A Few Clarifications, Plus More Than a Few Complications. Disponível em https://bit.ly/2TwSgZ7 Acesso em 16 de abril de 2020 


\section{VOZES $_{\text {\&DÁLOGO }}^{\mid}$}

Itajaí, V. 20, n.01, jan-jun 2027

LUNA FREIRE, Letícia de. Seguindo Bruno Latour: notas para uma antropologia simétrica. Disponível em https://inrcbage.files.wordpress.com/2011/09/latour.pdf Acesso em 18 de abril de 2020

MACHADO, Caio; KIRA, Beatriz; NARAYANAN; Vidya, KOLLANYI, Bence; HOWARD, Philip N. A Study of Misinformation in WhatsApp groups with a focus on the Brazilian Presidential Elections. In Proceedings of WWW '19: The Web Conference (WWW '19). Maio de 2019, San Francisco, USA. ACM, New York, NY, USA, 2019. https://doi.org/10.1145/3308560.3316738

PANG, Natalie; WOO, Yue Ting. What about WhatsApp? A systematic review of WhatsApp and its role in civic and political engagement. Disponível em https://firstmonday.org/ojs/index.php/fm/article/view/10417 Acesso: 10 de maio de 2020

PAPACHARISSI, Zizi. The virtual sphere: the internet as a public sphere. Disponível em http://nms.sagepub.com/cgi/content/abstract/4/1/9 Acesso em 16 de maio de 2020

PIAIA, V.; ALVES, M. Abrindo a Caixa Preta: análise exploratória da rede bolsonarista no WhatsApp. VIII Congresso da Associação Brasileira de Pesquisadores em Comunicação e Política, 2019, Brasília.

ROGERS, Richard. Digital Methods. The MIT Press, 2013.

WHATSAPP. Sobre o WhatsApp. Disponível em https://www.whatsapp.com/about/. Acesso em 21 de janeiro de 2021

. Política de Privacidade do WhatsApp. Disponível em https://www.whatsapp.com/legal/privacy-policy. Acesso em 29 de janeiro de 2021. 